\title{
Peer Assessment Experiences in the Lower Primary ESL Classrooms: Teachers' Perspectives
}

\author{
Amrien Hamila Ma'arop, Arshad Abd Samad* \\ Department of Language and Humanities Education, Faculty of Educational Studies, Universiti Putra Malaysia, Malaysia
}

Received October 27, 2019; Revised December 2, 2019; Accepted December 24, 2019

Copyright $\subseteq 2020$ by authors, all rights reserved. Authors agree that this article remains permanently open access under the terms of the Creative Commons Attribution License 4.0 International License

\begin{abstract}
Peer assessment is increasingly being emphasized as part of formative assessment due to its rich nature in developing independent and autonomous learners. However, in Malaysia, the practice of peer assessment is still limited. While past studies have indicated that conceptions predict classroom practices, and studying teachers' conception on peer assessment are important especially now that the transformation of assessment practice is a major item in the national educational agenda. Hence, this study aims to explore peer assessment experiences in the lower primary ESL classroom among teachers in the state of Selangor. The study adopted the qualitative research method, with three primary ESL teachers who were purposefully selected as the participants of the study. Data were collected through in-depth interviews and were analyzed for emerging themes. The findings revealed that participating teachers in this study viewed peer assessment as an interpersonal, intrapersonal and active, cognitive process. In implementing peer assessment, teachers generally engaged in several processes before and while implementing the activity. In the planning stage, the teachers decided on the activity and strategy, presented success criteria and specified feedback forms to be used by the students and while during the activity, teacher oriented the task clearly and facilitated the process through monitoring. This study contributed to a better understanding of teachers' perspectives on implementing peer assessment in the lower primary ESL classrooms in Malaysia.
\end{abstract}

Keywords Formative Assessment, Peer Assessment, English as a Second Language (ESL)

\section{Introduction}

Assessment is an important component in learning. Over the last thirty years, there has been growing evidence on the ability of assessment to improve student learning (William, 2017). From a process designed and implemented solely by the teacher, the assessment focus has now shifted to a more flexible process designed for student engagement and empowerment (Boud \& Falchikov, 2007). Unlike summative assessment which concerns itself with collecting information on how much learning has taken place, formative assessment encompasses "all those activities undertaken by teachers, and/or by their students, which provide information to be used as feedback to modify the teaching and learning activities in which they are engaged" (Black \& William, 1998, p. 140). Rather than focusing on grading and conducting on a one-off basis, formative assessment emphasizes on the learning process and is usually conducted in each lesson.

Like many other countries which are now making a shift to put more emphasis on formative assessment, Malaysia is also not excluded. In the Malaysian English Language Education Reform or what is commonly referred to as "The Roadmap 2015-2025", the assessment aspect has become a focus of transformation, alongside with the curriculum and the teaching and learning process, in the effort to produce quality student outcomes in English learning by 2025 (Ministry of Education, 2015). The implementation of formative assessment, which includes self-assessment and peer assessment, is strongly emphasized in the new curriculum. This type of assessment, when being planned instantaneously with the teaching and learning, serves as a connecting bridge that can accelerate learning (William, 2017).

Black and William (1998) and Falchikov (2005) consider peer assessment to be a strategy that places students at the center of formative assessment by encouraging them to evaluate and assess the quality of a piece of work produced by their peers using some form of success criteria. In peer assessment, students would not only be informed of their destination - where are we going? current location - where are we now?, and strategies - how do we get there?, but also participate in contribution - how 
can we help others in their learning? and reflection - "how can we be involved in making judgment about our own learning?". Peer assessment is therefore important in formative assessment due to its rich nature in developing independent and autonomous learners (Falchikov, 2013).

As key agents of educational assessment, teachers' role in the implementation of good assessment practices is significant (Veloo, Ramli \& Khalid, 2016; Black \& William, 1998). In facilitating students' learning and enhancing the quality of the teaching and learning process, teachers need to be able to create and implement valid and reliable assessments (Mellati \& Khademi, 2018). Without good assessment practices, teachers may not be able to help advance students' learning (Fook \& Sidhu, 2015). Nonetheless, previous studies in Malaysia revealed limited evidence of peer assessment in the primary ESL classroom (Sidhu, Kaur \& Chi, 2016; Sardaneh, 2018) and teachers' inadequate knowledge and skills in implementing such type of assessment are cited as one of the contributing factors for the lack of peer assessment occurring in Malaysian classrooms (Sardaneh, 2018, Mohamad Uri \& Abd. Aziz, 2018, Veloo et al., 2016).

Relating these findings to the theory of planned behavior (Ajzen, 2005) suggests that one's behavior is shaped by his or her personal belief, it seems important to view this issue from the teacher's conception and how it is translated to their practice. Past studies indicate that conceptions predict the practices that occur in the classrooms (Panadero \& Brown, 2017; Rubie-Davies, Flint \& McDonald, 2012). However, in Malaysia, previous studies on teachers' perception were mostly conducted within the secondary school or higher education context using self-reported questionnaires (Veloo et al. 2016, Majid, 2011). Research which focuses on teachers' conception and experience in implementing peer assessment in lower primary ESL context is scarce. Hence, this study aims to bridge the gap by exploring the issue within primary ESL context using qualitative methods. Studying teachers' conception on peer assessment is important now that the transformation of assessment practice is part of the educational agenda (Brown \& Harris, 2016).

This study aimed to explore peer assessment experiences in the lower primary ESL classroom among teachers in the state of Selangor. Two research questions that guided the study are: (1) what is the ESL teachers' understanding of the meaning of peer assessment in ESL context? and (2) how do ESL teachers implement peer assessment in the lower primary ESL classroom?

\section{Literature Review}

\subsection{Peer Assessment}

Peer assessment is a type of 'Assessment for Learning' (Black \& William, 1998) which actively involves students in the assessment process by having them to evaluate the quality of work produced by a peer (Falchikov, 1995; Topping, 2009). It is a process where students consider and specify the level and value of a product or performance of other equal-status learners. (Topping, 2009, p.20). In peer assessment, students reflect, discuss and collaborate with their peers in order to make a quantitative and/or qualitative judgment of their peer's work (Strijbos \& Sluijsmans, 2010) in a variety of learning products such as essays, writing portfolios, test performance, oral presentations and other skilled behaviors (Topping, 2009).

Previous literature summarizes important planning issues related to peer assessment (Topping, 2003; Smith, Cooper\& Lancaster, 2002; Topping \& Ehly, 2001; Webb \& Farivar, 1994) which are listed as follows:

1. State the aim for the activity - whether the aims would lead to gains in cognition, attitudes, social or emotional aspects. In this regard, the nature of the learning products to be assessed should also be specified.

2. Involve participants in developing and clarifying assessment criteria in order to create a sense of ownership. Ideas relevant to the activity should be discussed with the students early and periodically throughout the activity in order to obtain feedback and acceptance of the activity or scheme. 9Ideally, small group discussions of draft criteria proposed by the teacher should lead to a small degree of suggested change after such discussions,

3. Match participants and arrange for contact. If possible, participants should be matched with others who share the same abilities,

4. Provide training, examples and practice. Quality training can have a noticeable difference,

5. Provide tangible forms of scaffolding such as guidelines and checklists. "A clearer view of "what you have to do to be right' is likely to improve assessed performance, especially when the criteria for assessment have been discussed or negotiated with all participants" (Topping \& Ehly, 2001, p. 118),

6. Specify activities and timescale,

7. Monitor and coach. In peer assessment among students in the classroom, the teacher should keep a low profile and observe the students, giving feedback and coaching when required,

8. Examine the quality of peer feedback,

9. Moderate the reliability and validity of feedback,

10. Evaluate the peer-assessment activity and provide feedback to the participants,

Past studies have also revealed substantial evidence that peer assessment can result in better quality of learning (Topping, 2009). Feedback during peer assessment, given either in confirmatory, suggestive or corrective forms, is able to reduce errors and has positive effects on learning when being accepted thoughtfully and positively (Topping, 2009). This process is also important in the development and execution of self-regulatory skills (Butler \& Winne, 
1995). The benefits of peer assessment from various perspectives are discussed in the following sub-sections.

\subsection{Cognitive Gains}

Peer assessment benefits not only the assessors but also those being assessed. In order for students to evaluate their classmates' performances and accept the feedback given in peer assessment process, they engage in high level cognitive and discursive processes that include questioning, negotiating and the articulation of their thoughts (Kollar \& Fischer, 2010). Peer assessment enables students to identify and analyze previous errors committed and misconceptions held which eventually lead them to self-discover the current knowledge gaps in their learning (Topping, 2009). They have to be actively engaged in the learning process as they compare the work of others in relation to specified criteria (Harris \& Brown, 2016; Panadero \& Brown, 2017; Topping, 2010)

In addition, long-term engagement in peer assessment will require teachers to ensure that students are involved in high quality tasks as well as develop "passionate positive feelings about these tasks" (Munn \& Woodward, 2006, p.197). Previous studies revealed that students' engagement in this activity impacts positively on their cognitive development and enjoyment of learning (Fredricks, Blumenfeld \& Paris, 2004).

\subsection{Social Gains}

Peer assessment can be considered as a social process in which Vygotsky's social constructivist theory functions as the underlying theoretical rationale (Falchikov \& Goldfinch, 2000). In a social constructivist framework, the teacher plays the role of a guide and the peer assessor as "little teacher", and together work to make peer assessment a student-centered activity that involves interactional learning (Rotsaert, Panadero \& Schellens, 2018). Peer assessment is fundamentally an interpersonal process as it allows students to participate in collaborative appraisal through the use of multiple perspectives gained through the incorporation of peer opinions and viewpoints (Panadero, 2016) which at the same time can develop collaborative and teamwork skills (Riley, 1995).

However, researchers also argue that friendship bonds have been identified as a source of potential feedback bias in peer assessment (Rotsaert el al., 2018; Raes, Banderhovem \& Scjelens, 2013). Students generally have strong feelings and needs to feel comfortable with the person giving feedback and they are more likely to accept feedback when the focus is on positive aspects of their work (Dorrington \& van Nieuwerburgh, 2015). Nevertheless, pressure because of friendship with peers might result in peer assessment that is unfair or a refusal to participate in the assessment (Raes et al., 2013).

\subsection{Personal Gains}

Peer assessment allows students to play an active role in managing their learning. This is an important element of self-regulated learning in which students monitor their work through feedback they receive from external sources such as from peers given during collaborative group meetings (Butler \& Winne, 1995).

According to Gipps (1999, p.383), 'passing responsibility for assessment to the student' is crucial as it helps 'to develop' them 'as self-monitoring learners'. Not only peer assessment helps students gain confidence in evaluation and commentary (Chen, 2006), but it also prepares them for life-long learning process (Dekain-Crick et al., 2005).

\section{Methodology}

The study utilized qualitative research methods in exploring peer assessment experiences among teachers in the primary ESL classroom. Three primary ESL teachers were purposefully selected to be the participants of the study. They were chosen because they met the following criteria:

(a) they are English teachers in a Malaysian public primary school in Selangor,

(b) they teach English in a lower primary classroom (Year 1, Year 2, Year 3),

(c) they implement peer assessment in their lessons,

(d) they have a minimum of three years of teaching experience,

(e) they hold at least a Bachelor's degree in Teaching English as a Second Language (TESL),

(f) they are "interested in understanding the nature and meanings of peer assessment and willing to participate in a lengthy interview (perhaps a follow-up interview)", (Moustakas, 1994, p.107) and

(g) they agree for the interview to be recorded.

Data were gathered through an in-depth interview in order to examine the teachers' perceptions towards their experience with peer assessment. The interview method was used as thoughts, feelings and intentions that cannot be directly observed (Patton, 2015). These individual interview sessions were conducted face-to-face at a time and place agreed upon by the respondents. Each session took between twenty to thirty minutes with a follow-up interview to obtain additional information and clarification, and upon the respondents' approval. The semi-structured interview model was adopted as it was considered the most appropriate method for the researcher to explore the central issues that are raised by the research questions.

The interviews were recorded using a voice recorder after obtaining the approval of the participants and were then subsequently transcribed for analysis. During the interview, the researcher also engaged in "memoing" 
(Miles \& Huberman, 1994, p. 72) to allow for reflection to take place within the context of the interviews and for the collection of non-standard and extra-linguistic data such as gestures, facial, as well as other non-verbal forms of expression (Creswell, 2011).

In this study, data analysis began after the first interview was conducted. Once the interview was transcribed, the researcher read through the transcription in order to obtain a general sense of the interviewees' responses and to subsequently engage in the coding process. This process began with open coding and axial coding (Corbin \& Strauss, 2015) before themes that addressed the research questions of the study were identified.

To ensure the internal validity and credibility of the study, the analysis went through a member checks process in which the participants were invited to review the initial coding done by the researcher and were asked to comment on the accuracy of the coding. Discussion and further interviews were conducted if coding was found to be misleading or ambiguous, or if further explanation was provided by the participants. In terms of reliability of the study, an audit trail was used to retrace the process used by the researcher to arrive at the findings.

Several measures were taken in order to ensure ethical concerns were properly dealt with. Firstly, before data collection began, approval was obtained from the participants. Participants were informed that their participation in this study was voluntary and that they were free to withdraw from the study whenever they felt they wanted to. The participants also ensured of the confidentiality of all their personal information as well as their responses during the interviews. They were assured that pseudonyms would be used in reporting the findings and only the researcher would have access to the data.

\section{Results}

\subsection{Informant Profile}

This study involved three informants. All the informants are primary school English teachers from various districts in Selangor. They are between 26 to 32 years old, and their teaching experience ranges from three to nine years. They all graduated from different campuses of a teacher training institute and are currently teaching lower primary classes. The table below summarizes the informants' background profile:

Table 1. Summary of Informants' Background Profile

\begin{tabular}{|c|c|c|c|c|c|}
\hline $\begin{array}{c}\text { Informant } \\
\text { (Pseudonym) }\end{array}$ & Age & $\begin{array}{c}\text { Years of Teaching } \\
\text { Experience }\end{array}$ & $\begin{array}{c}\text { Classes } \\
\text { Taught }\end{array}$ & $\begin{array}{c}\text { Location of } \\
\text { School }\end{array}$ & Student's Level of English Proficiency \\
\hline Erna & 29 & 6 & Year 1 \& 2 & Sepang & $\begin{array}{c}\text { Mixed - high, medium, low } \\
\text { (English as medium of instruction) }\end{array}$ \\
\hline Hawa & 32 & 9 & Year 1 & Kuala Langat & $\begin{array}{c}\text { Mixed - medium, low } \\
\text { (English \& Malay as medium of } \\
\text { instruction) }\end{array}$ \\
\hline Kamila & 26 & 3 & Year 1 \& 2 & Klang & $\begin{array}{c}\text { Mixed - medium, low } \\
\text { (English and Malay as medium of } \\
\text { instruction) }\end{array}$ \\
\hline
\end{tabular}


The first informant, Erna, who has six years of teaching experience, is currently teaching in one of the schools in Sepang district. The school is listed under the Trust School Programme, which is regarded as a comprehensive and sustainable school transformation programme that is intended to improve student outcomes and revitalize school culture and in which formative assessment is one of the core elements in the lesson planning format. The students come from various socio-economic backgrounds (SEB), but mostly are of medium to high SEB. Although the students have mixed-ability in English, most of the students can understand English which enables classroom instructions to be given in English.

The second informant, Hawa, has nine years of teaching experience. She is an English teacher in one of the schools in Kuala Langat district, a suburban area in Selangor. The students in this school come from various SEB, ranging from low to medium SEB. The students are of low to medium levels of English proficiency which require lessons and classroom instructions to be delivered bilingually - Malay and English.

The last informant, Kamila, is the youngest participants in this study. She is a new teacher with three years of teaching experience. She teaches in one of the schools in Klang district. Although Klang is located near to Kuala Lumpur and can be considered as an urban area, most of the students come from low to medium SEB. Similar to Hawa, her students have low to medium levels of English proficiency and thus requiring her to deliver the lessons in both Malay and English in order for the students to understand.

Research Question 1: What is the ESL Teachers' Understanding of the Meaning of Peer Assessment in ESL Context?

Based on the interviews conducted, it was found that teachers' understanding of the meaning of peer assessment can be discussed under three themes namely:

i. Peer assessment as an active cognitive process

ii. Peer assessment as an interpersonal process

iii. Peer assessment as intrapersonal process

\subsection{Peer Assessment as an Active Cognitive Process}

The interviews with the informants revealed that the teachers viewed peer assessment as an active cognitive process. Peer assessment, which requires students to evaluate the work of their peers, gets students to engage in various thinking processes such as comparing and contrasting, identifying similarities and differences, as well as identifying strength and weaknesses. The processes make students become attentive of the learning process. This was admitted by Hawa who claimed that peer assessment makes students "...become aware. They are active. They engage in the process...". The same views were shared by Erna who asserted that peer assessment enables students to "...compare their work with their friend's work. It is easier for them to notice any mistakes or errors committed when checking other's work as they get to see the similarities and differences between their work and their friend's work...". As pointed out by Nicol, Thomson and Breslin (2014), in peer assessment, students spend time thinking, comparing, contrasting and communicating which locate them in deep cognitive learning. This activity thus requires them to be active participants in their own learning.

\subsection{Peer Assessment as an Interpersonal Process}

Based on the interviews with the informants, it was found that the teachers perceived peer assessment as an interpersonal process. Considering the age of the students who are still developing their interpersonal relationship with their peers in the classroom, peer assessment was seen as an opportunity for students to participate in the socialization process. As shared by Erna, “...students share and exchange their work with a partner or group member...they discuss their answers or ideas together...". This experience was similar to Hawa who stated that "...students swap their books...they talk to each other about the answers..." These show the potential role of peer assessment as a socialization platform which promotes interaction among peers.

Moreover, peer assessment could also be regarded as a platform to mark friendship among the classmates. As described by Kamila,

“...In my class, there's a few who are best friends. They are excited to mark each other's work. But if they are not in very good terms with each other, they were like, "hey, you did not know this one?" From this activity, we can discover that this person likes that person and that person does not like that person. From there, we learn that perhaps next time we could change their partners..."

Hawa related her experience as follows:

"There are cases when they are good friends...they ask their peer to correct their initial answer. They erase their friend's answer and write the right answer. "I will correct yours and you will correct mine." They wanted to avoid having to do correction afterwards".

These scenarios provide us with evidences on how peer assessment is a platform for the interpersonal process. This is consistent with the views of Panadero (2016) which highlighted peer assessment as an interpersonal process as it generates thoughts, actions, motivational outcomes, and emotions for both assesses and assesses. Therefore, it is important for teachers to consider the effect of friendship bonds on the outcomes of peer assessment activity so as to be able to provide adequate social-affective support (Murdock, Stephen \& Grotewiel, 2016).

\subsection{Peer Assessment as an Intrapersonal Process}

The interviews also indicated that the informants 
considered peer assessment as an intrapersonal process. In the process of assessing and evaluating the work of their peers, students did not only engage in negotiation and clarification, but also monitored their own work. This is admitted by Hawa who claimed that,

"...sometimes, there are students who not only mark their own work, but they keep checking on their work that is being assessed by their friend... They will actually check if they do it right or wrong. Actually, at the back of their mind, they are very aware of what they did. So, when they correct their friend's mistake, they are actually learning."

The same views were expressed by Erna who stated that: “...by checking one's work, students not only learn to evaluate their friends but also themselves...by identifying their own weaknesses and learning to correct their friends' work, students can know what and how they can do better. This would help them to improve their learning"

Assessing others' work during peer assessment enables students to generate internal feedback that they could use to inform their own work (Nicol, Thomson \& Breslin, 2014). This would eventually lead them to monitor their own learning and thus take full ownership of their learning process (Butler \& Winne, 1995).

Peer assessment also boosted students' self-esteem. Assessing other people's work makes students become more confident in their ability. As pointed out by Kamilla, “...peer assessment is important because it gives a sense of confidence to the students that they know what is right and what is wrong...”. Similarly,. Erna also stated that “...they like it so much especially when we give them permission to mark with whatever color pencil that they like. They feel like a teacher. They feel confident..." The findings are similar with the views of Hung (2018) who asserts that scoring others, which empowered students as "little teachers" in classrooms in which teachers maintain sole authority, gave the students enjoyment and eventually led them to gain confidence in their ability to assess the work of their peers.

Research Question 2: How do ESL Teacher Implement Peer Assessment in the Lower Primary ESL Classroom?

Based on the interviews conducted, it was found that the ways teachers implement peer assessment can be discussed under two themes namely:

i. Planning stage

ii. Implementation stage

\subsection{Planning Stage}

The results from the interview revealed that teachers generally engaged in a few processes in the planning stage of peer assessment. First, teachers made decisions on activities or students' products that need to be peer reviewed. The three informants generally use peer assessment in activities like 'spelling', 'writing sentences or short essays' and 'poster or drawing' presentation. As pointed out by Topping (2009), in peer assessment, a wide variety of student products or outputs can be peer assessed, including essays, portfolios, oral presentations and other forms of skilled behaviours.

Then, they would decide on the strategies for conducting peer assessment. The most common strategies used are exchanging work with a peer next to the student or working in groups. As shared by Kamilla, “...sometimes, I asked the students to work in groups and evaluated the work of other groups...some other time, I just get them to swap their work with the person sitting next to them..."

Another process involved in the planning stage is to prepare the success criteria. The success criteria normally used by the informants were guidelines, checklists or just a list of right or wrong answers. As pointed out by Erna, "...sometimes, I give them checklist. The most common one is writing checklist. For example, when they write sentences, they need to have capitalization, full stop, correct spelling...". Using checklist is important as it helps students produce comments that are relevant and justified (Boon, 2016).

Once the success criteria have been presented, the teachers specified the forms of feedback that the students will use when evaluating the friends' work. The forms of feedback commonly used by the students in the informants' classrooms were either in word form like phrases, numerical form like marks or grades or, visual form like stars, stickers or smiley face. For example, Hawa in relating her experience conducting peer assessment mentioned that "...but the response in non-words. They give stickers. If they like, they give stars. If they don't like, they don't give stars. Or they draw likes, they draw smiley faces." A similar experience was shared by Erna who said that "...they can use simple way such as drawing smiley faces or stars, using stickers and writing a simple word...". In this respect, it is interesting to note research by Crews and Wilkinson (2010) on students' perception that indicated a preference for visual and auditory feedback and that visual, auditory and e-handwritten feedback was able to help the students understand the types of errors they were making and the reasons as to why the errors were incorrect.

\subsection{Implementation Stage}

The results also indicated that during the implementation stage, it is important for teachers to give clear orientation of the task to the students. The teachers first explained the task to the students. This is a crucial step because students' inability to understand the task would make them unable to perform the task as expected. As expressed by Erna, “....we need to brainstorm the task with the student...or else the students did not know what to write...". This is consistent 
with the previous findings which suggest that teachers state the aim for the activity and specify the nature of the learning products to be assessed at the early stage of the process (Topping, 2003; Webb \& Farivar, 1994).

The teachers also discussed the success criteria with the students and gave them opportunities to contribute to the development of the success criteria. As pointed out by Erna, "...students have the right to be given the chance to do things on their own...I ask for their ideas. I ask them to add other words. For high achieving students for example, they can suggest more advanced words to be used as feedback...".

The findings also revealed that teachers generally played a role in facilitating the process of peer assessment. One of the examples was to assist low achieving students to be assessors. As explained by Kamila, “...for low achieving students, we can give suggest them words to use...we can monitor how they are doing...". The teachers also reminded the students that they should be using constructive feedback in commenting. As expressed by Hawa, "...sometimes they give negative feedback...so we should remind them to give constructive feedback...". Constructive feedback is a key element in the successful implementation of assessment for learning (Kollar \& Fischer, 2010). Hence, it is essential for teachers to model appropriate comments to be given in peer assessment and to assist students in learning how they should give and take comments in an appropriate and positive manner (Hung, 2018).

\section{Conclusions}

This study explored peer assessment experiences among ESL lower primary teachers in Selangor. It found that the participating teachers viewed peer assessment as an active, cognitive process, as well as an interpersonal and intrapersonal process. The teachers in this study responded positively to peer assessment and regarded it as a rich and meaningful learning experience for the students. In implementing peer assessment, the teachers generally engaged in several processes before and while implementing the activity. In the planning stage, the teachers decided on the activity and strategy, presented success criteria and specified feedback forms to be used by the students while during the activity, teacher oriented the task clearly and facilitated the process through monitoring. Based on their responses in the interview, this study has demonstrated that teachers in lower primary classrooms implemented peer assessment activities. A better picture of how the implementation process takes place may have been better described through observation, which, because it was not used is a limitation of this study.

\section{REFERENCES}

[1] Ajzen, I. (2005). Attitudes, personality, and behavior (2nd ed.). New York: Open University Press.

[2] Black, P. \& William, D. (1998). Inside the black box: Raising standards through classroom assessment. The Phi Delta Kappan, 80 (2), 139-148.

[3] Boud, D. \& Falchikov, N. (2007). Introduction: Assessment for the longer term. In Boud, D. \& Falchikov, N. (Eds.). Rethinking assessment for higher education: Learning for the longer term (pp. 3-13). London: Routledge.

[4] Boon, S. I. (2016). Increasing the uptake of peer feedback in primary school writing: Findings from an action research enquiry. Education 3-13, 44 (2), 212-225.

[5] Brown, G.T.L \& Harris, L.R. (2016). Handbook of human and social conditions in assessment. New York, NY: Routledge.

[6] Butler, D. \& Winne, P. (1995). Feedback and self-regulated learning: A theoretical synthesis. Review of Educational Research, 65 (3), 245-281.

[7] Chen, Y.M. (2006). Peer and self-assessment for English oral performance: A study of reliability and learning benefits. English Teaching \& Learning, 30 (4), 1-22.

[8] Corbin, J. \& Strauss, A. (2015). Basics of qualitative research: techniques and procedures for developing grounded theory (4th ed.). Thousand Oaks, CA: Sage.

[9] Creswell, J.W. \& Poth, C.N. (2018). Qualitative inquiry and research design: Choosing among five approaches (4th ed.). Thousand Oaks, CA: Sage Publications Inc.

[10] Denscombe, M. (2014). The good research guide: For small-scale social research projects (5th ed.). Maidenhead: Open University Press.

[11] Dorrington, L. \& van Nieuwerburgh, C. (2015). The development of peer coaching skills in primary school children: An exploration of how children respond to feedback. International Journal of Information and Education Technology, 5 (1), 50-54.

[12] Falchikov, N. (1995). Peer feedback marking: Developing peer assessment. Innovations in Education and Training International, 32 (2), 175-187.

[13] Falchikov, N. (2005). Improving assessment through student involvement: Practical solutions for aiding learning in higher and further education. London: Routledge.

[14] Falchikov, N. \& Goldfinch, J. (2000). Student peer assessment in higher education: A meta-analysis comparing peer and teacher marks. Review of Educational Research, 70, pp. 287-322.

[15] Fook, C.Y. \& Sidhu, G.K. (2015). School-based assessment among ESL teachers in Malaysian secondary schools. Malaysian Education Deans' Council Journal, 9, 75-87.

[16] Field, P.A \& Morse, J.M. (1985). Nursing research: The application of qualitative methods. London: Croom Helm.

[17] Gipps, C. (1999). Socio-cultural aspects of assessment. Review of Research in Education, 24 (1), 355-392.

[18] Harris, L.R. \& Brown, G.T.L. (2016). Volume introduction: 
The human and social experience of assessment: Valuing the person and context. In G.T.L. Brown, \& L.R. Harris (Eds.). Handbook of human and social conditions in assessment (pp. 1-17). New York, NY: Routledge.

[19] Hung, Y. (2018). Group peer assessment of oral English performance in a Taiwanese elementary school. Studies in Educational Evaluation, 59 (2018), 19-28.

[20] Lincoln, Y. \& Guba, E. (1985). Naturalistic enquiry. Beverly Hills, CA: Sage.

[21] Kollar, I. \& Fisher, F. (2010). Peer assessment as a collaborative learning: A cognitive perspective. Learning \& Instruction, 20 (4), 344-348.

[22] Lodico, M.G., Spaulding, D.T., \& Voegtle, K.H. 2010. Methods in Educational Research: From Theory to Practice. San Francisco, CA: Wiley.

[23] Majid, F. (2011). School-based assessment in Malaysian schools: The concerns of the English teachers. Journal of US-China Education Review, 8 (10), 1-15.

[24] Maxwell, J.A. (2013). Qualitative research design: An interactive approach (3rd ed.). Thousand Oaks, CA: Sage.

[25] Mellati, M. \& Khademi, M. (2018). Exploring teachers' assessment literacy: Impact on learners' writing achievements and implications for teacher development. Australian Journal of Teacher Education, 43 (6), 1-18.

[26] Merriam, S.B. \& Tisdell, E.J. (2016). Qualitative research: a guide to design and implementation (4th ed.). San Francisco, CA: Jossey-Bass.

[27] Miles, M.B. \& Huberman, A.M. (1994). Qualitative data analysis: An expanded sourcebook. Thousand Oaks, CA: Sage.

[28] Mohamad Uri, N.F. \& Abd. Aziz, M.S (2018). Implementation of CEFR in Malaysia: Teachers' awareness and the challenges. The Southeast Asian Journal of English Language Studies, 24 (3), 168-183.

[29] Moustakas, C. 1994. Phenomenological Research Methods. Thousand Oaks, CA: Sage.

[30] Munn, G. \& Woodward, H. (2006). Student engagement and student self-assessment: The REAL framework. Assessment in Education, 13 (2), 193-213.

[31] Murdock, T.B., Stephens, J.M., \& Grotewiel, M. (2016). Student dishonesty in the face of assessment: Who, why, and what can we do about it. In G.T.L Brown, \& L.R. Harris (Eds.). Handbook of human and social conditions in assessment (pp. 1-39). New York, NY: Routledge.

[32] Nicol, D., Thomson, A. \& Breslin, C. (2014). Rethinking feedback practices in higher education: A peer review perspective. Assessment and Evaluation in Higher Education, 35 (5), 501-517.

[33] Panadero, E. (2016). Is it safe? Social, interpersonal, and human effects of peer assessment: A review of future directions. In G.T.L Brown, \& L.R. Harris (Eds.). Handbook of human and social conditions in assessment (pp. 247-266). New York, NY: Routledge.

[34] Panadero, E. \& Brown, G.T.L. (2017). Teachers' reason for using peer assessment: Positive experience predict use.
European Journal of Psychology of Education, 32 (1), 133-156.

[35] Patton, M.Q. (2015). Qualitative research and evaluation methods (4th ed.). Thousand Oaks, CA: Sage.

[36] Rotsaert, T., Panadero, E. \& Schellens, T. (2018). Peer assessment use, its social nature challenges, and perceived educational value: A teachers' survey study. Studies in Educational Evaluation, 59 (2018), 124-132.

[37] Rubie-Davies, C.M, Flint, A. \& McDonald, L.G. (2012) Teacher beliefs, teacher characteristics, and school contextual factor: What are the relationships? British Journal of Educational Psychology, 82, 270-288.

[38] Saldana, J. (2013). The coding manual for qualitative researchers (2nd ed.). Thousand Oaks, CA: Sage.

[39] Sardaneh, S.A. (2016). Formative feedback in a Malaysian primary school ESL context. Malaysian Online Journal of Educational Sciences, 4 (1), 1-8.

[40] Sidhu, G.K., Kaur, S., \& Chi, L.J. (2016). CEFR-aligned school-based assessment in the Malaysian primary ESL classroom. Indonesian Journal of Applied Linguistics, 8 (2), 452-463.

[41] Smith, H., Cooper, A., \& Lancaster, L. (2002). Improving the quality of undergraduate peer assessment: A case for student and staff development. Innovations in Education and Teaching International, 39 (1), 71-81.

[42] Strijbos, J.W. \& Sluijsmans, D. (2010). Unravelling peer assessment: Methodological, functional, and conceptual developments. Learning and Instruction, 20, 265-269.

[43] The Glossary of Education Reform. (2014). Formative assessment. Retrieved December 28, 2018, from http://edgl ossary.org/formative-assessment/

[44] Topping, K.J. (2003). Self and peer assessment in school and university: reliability, valididty and utility. In M. Segers, F. Dochy, \& E. Cascallar (Eds.). Optimizing new modes of assessment: In search of qualities and standards (pp. 55-87). Dordrecht, The Netherlands: Kluwer Academic.

[45] Topping, K.J. (2009). Peer assessment. Theory into Practice, 48 (1), 20-27.

[46] Topping, K.J. \& Ehly, S.W. (2001). Peer assisted learning: a framework for consultation. Journal of Educational and Psychological Consultation, 12 (2), 113-132.

[47] Veloo, A., Ramli, R. \& Khalid, R. (2016). Assessment practices among English teachers in Malaysian secondary schools. International Journal for Infonomics, 9 (4), 1220-122.

[48] Webb, N.M. \& Farivar, S. (1994). Promoting helping behavious in cooperative small groups in middle school mathematics. American Educational Research Journal, 31 (2), 369-395. 